\title{
CAN WE DECREASE RECURRENCE OF OSSN USING MITOMYCIN C
}

\author{
Dr. Mohammed Ather* ${ }^{1}$, Dr. Nasreen ${ }^{2}$, Dr. T. Kavitha ${ }^{3}$, Dr. Kesava Rao ${ }^{4}$, Dr. Sara Sultana ${ }^{5}$, Dr. Sharf Amena ${ }^{6}$ \\ ${ }^{1}$ Professor of Ophthalmology, Gandhi Medical College/ In charge department of Oculoplasty SD eye hospital, \\ Hyderabad, Telangana state, India \\ ${ }^{2}$ Assistant Professor of Pharmacology, Osmania Medical College, Hyderabad, Telangana State, India \\ ${ }^{3}$ Pathologist, Sarojini Devi Eye Hospital, Regional institute of Ophthalmology, Hyderabad. Telangana State, India \\ ${ }^{4}$ Assistant professor of Ophthalmology, Gandhi Medical College, Musheerabad, Telangana State, India \\ ${ }^{5}$ Junior resident of Ophthalmology, Sarojini Devi Eye Hospital, Hyderabad, Telangana State, India \\ ${ }^{6}$ Junior resident of Pathology, Osmania Medical College, Hyderabad, Telangana state, India \\ *Corresponding Authors Email ID: ather11258@gmail.com
}

Received 19 Nov 2014; Review Completed 07 Jan 2015; Accepted 13 Jan 2015, Available online 15 Jan 2015

\begin{abstract}
:
Aim: To study the effect of topical Mitomycin C on recurrence of OSSN after surgical excision.

Materials and methods: This is a Randomized prospective interventional study conducted at Sarojini Devi Eye Hospital /Regional institute of Ophthalmology, Hyderabad. 54 clinically diagnosed cases of OSSN attending department of Oculoplasty between October 2012 to September 2014 were included in the study. 36 were males and 18 were females. Cases already treated were excluded from the study. These cases were randomly divided into two groups of 18 males and 9 females. Both the groups were treated by surgical excision of OSSN with $3 \mathrm{~mm}$ margin of normal conjunctiva and cryo applied to the bare area by freeze thaw freeze technique. Group A was followed up every month for recurrence. Group B were given topical Mitomycin C $0.04 \%$ drops 4 times daily for 4 days in a week with 3 days off. This constitute one cycle. Patients were kept for 4 cycles on this therapy. This group is also followed up every month for recurrence up to 2 years.

Results: In group A 4 cases (14.8\%) developed recurrence of tumor within one year. In group B there was no recurrence. Conclusion: Mitomycin C as adjuvant therapy after surgical excision of OSSN is effective in preventing recurrence. Key words: OSSN (Ocular surface squamous neoplasia), MMC (Mitomycin C), HIV (Human immuno-deficiency virus), HPV (Human papilloma virus).
\end{abstract}

\section{INTRODUCTION:}

Ocular surface squamous neoplasia was first described by Lee and Hirst ${ }^{1}$ In 1995 as an umbrella term that denotes spectrum of neoplasia originating from squamous epithelium ranging from dysplasia to invasive squamous cell carcinoma. OSSN incidence is increasing throughout the world with higher frequency in the equatorial region. Variety of etiological factors like HIV, HPV infections, exposure to UV rays are attributed. ${ }^{2}$ Mitomycin $\mathrm{C}$ had been used alone or as adjuvant therapy after surgical excision in various studies. $^{3}$

Aim: To study the effect of Mitomycin C on recurrence of OSSN after surgical excision.

\section{MATERIALS AND METHODS:}

This is a Randomized prospective interventional study conducted at Sarojini Devi Eye Hospital, Hyderabad between October 2012 to September 2014 in the department of Oculoplasty. 54 patients 36 males 18 females who were clinically diagnosed as OSSN by slit lamp examination by an experienced Ophthalmologist were included in the study. Cases who underwent treatment were excluded from study. 54 cases were randomly divided into two groups of 18 males and 9 females. Informed consent taken after explaining the procedure in the patient's own language. Routine surgical profile was performed. All 54 cases were subjected to surgical excision of OSSN under topical anaesthesia of $4 \%$ Lignocaine drops with Local infiltration of $2 \%$ Lignocaine around the tumour. OSSN was excised using Crescent blade of small incision cataract surgery with $3 \mathrm{~mm}$ of normal conjunctival margin $^{4}$. Cryo applied to bare area with Freeze-thawFreeze technique for thirty seconds with $5 \mathrm{~mm}$ cryoprobe. 5,6

Group A were followed up every month for recurrence up to 2 years. Group B were given topical Mitomycin C drops $0.04 \%$ one drop four times daily for 4 days a week with 3 days off. This constitutes one cycle and patients were asked to use drops for four cycles. These 
patients were also followed up every month for a period of 2 years.

\section{RESULTS:}

In Group A, 4 cases (14.8\%) had recurrence within one year. All 4 were males. Group B had no recurrence even after two years.

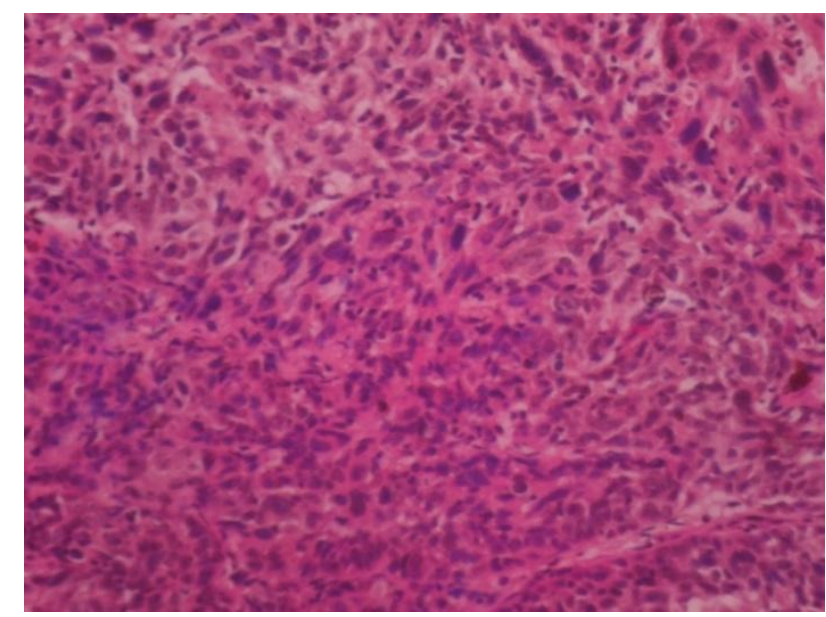

Figure 1: Showing squamous cell carcinoma.

\section{DISCUSSION:}

Studies conducted elsewhere in the world showed similar results. H C Russell et al used MitomycinC alone in 58 cases of OSSN. They reported nil recurrence in Conjunctiva cornea intraepithelial neoplasia. Recurrence occurred in $6.8 \%$ cases that had Invasive squamous cell carcinoma. ${ }^{7}$

\section{REFERENCES:}

1. Lee \& Hirst Retrospective of OSSN Aus NZJ of Ophthalmology 1997;25:269

2. Winward et al conjunctival squamous cell carcinoma in HIV case AMJ of Ophthalmology 1989;107:554.

3. Goodman \& Gilman, Pharmacological basis of disease, $11^{\text {th }}$ edition 2005

4. Shields et al june 1997; Arch. Of ophthalmology, vol. 115 (6) page $805-815$
A Gupta et al used MMC in 73 cases of OSSN which had a mix of primary tumors and recurrence tumors. There was no recurrence in primary tumors. ${ }^{8}$

No recurrence was reported by $\mathrm{C}$ Chen et al who had used MMC drops as adjuvant after surgical excision of OSSN in 27 cases. ${ }^{9}$

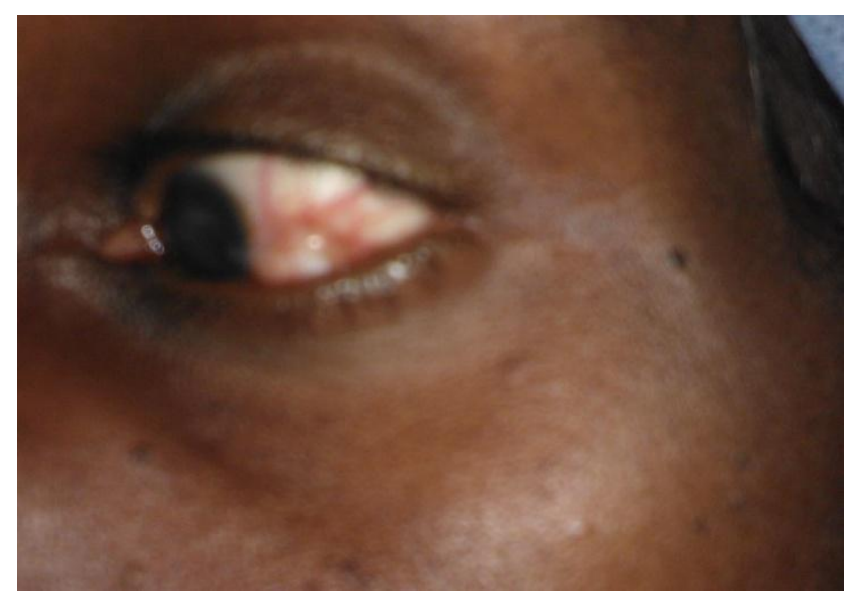

Figure 2: Clinical picture of OSSN

\section{CONCLUSION:}

It is concluded that use of MMC drops as adjuvants after surgical excision is effective in preventing recurrence.

\section{Conflict of interest: nil.}

